\title{
Involvement of Autoimmune Diseases in the Pathogenesis of Chronic Immune Thrombocytopenic Purpura
}

\author{
Mădălina Mocanu1, Magda Bădescu1 ${ }^{*}$, Manuela Ciocoiu1 ${ }^{1}$, Codruța Bădescu², \\ Cristina Elena Iancu ${ }^{3}$, Oana Bădulescu ${ }^{1}$ \\ ${ }^{1}$ Department of Pathophysiology, “Grigore T. Popa” University of Medicine and Pharmacy, Iaşi, Romania \\ ${ }^{2}$ Department of Internal Medicine, "Grigore T. Popa" University of Medicine and Pharmacy, Iaşi, Romania \\ ${ }^{3}$ Deparment of Pharmaceutical Science II, "Grigore T. Popa" University of Medicine and Pharmacy, laşi, Romania \\ Email: *magda.badescu@gmail.com
}

Received 12 February 2015; accepted 15 March 2015; published 17 March 2015

Copyright (C) 2015 by authors and Scientific Research Publishing Inc.

This work is licensed under the Creative Commons Attribution International License (CC BY). http://creativecommons.org/licenses/by/4.0/

(c) (i) Open Access

\section{Abstract}

Chronic immune thrombocytopenic purpura (ITP) is a condition based on an immune-mediated mechanism that determines the premature hyperdestruction of the thrombocytes in peripheral blood, as well as their deficient synthesis at the level of the bone marrow. The chronic immune purpura could be of primary, idiopathic cause, as well as of secondary cause, occurring in the context of other pathologies. The characteristic of the primary form of the disease is the presence of isolated thrombocytopenia, defined by a platelet count under $100,000 / \mathrm{mm}^{3}$ in peripheral blood, in the absence of supporting causes for thrombocytopenia. In the secondary form of the disease, the decreased platelet count is due to associated pathologies involving an immune mechanism, responsible for the occurrence of thrombocytopenia. This study aims to emphasize the involvement of autoimmune diseases, such as systemic lupus erythematosus (SLE), dermatomyositis, rheumatoid polyarthritis or antiphospholipid syndrome in the pathogenesis of secondary thrombocytopenia. Furthermore, the study was conducted on a sample of 40 patients, divided into two groups: The first group comprising asymptomatic patients diagnosed with thrombocytopenia following routine tests, and the second group comprising patients with hemorrhagiparous symptomatology (petechiae, ecchymoses, epistaxis, gingivorrhagia), who went to the doctor in order to determine the etiology of the hemorrhagiparous syndrome. The average value of the thrombocytopenia of the patients included in the study was of $60.20 \pm 19.75 \times 10^{3} / \mu \mathrm{L}$. Laboratory investigations performed in order to establish the etiology of thrombocytopenia showed that $80 \%$ of patients presented positive antiplatelet antibodies. Moreover, $20 \%$ of the patients in the study showed positive anti-double-stranded DNA, $20 \%$ were identified with IgG anticardiolipin antibodies, while antinuclear antibodies were present in $10 \%$ of the patients.

\footnotetext{
"Corresponding author.
} 


\section{Keywords}

\section{Thrombocytopenic Purpura, Antiplatelet Antibodies, Systemic Lupus Erythematosus,} Antiphospholipid Syndrome

\section{Introduction}

Immune thrombocytopenic purpura (ITP) is a condition characterized by peripheral platelet hyperdestruction exceeding the capacity of compensatory thrombopoiesis of the bone marrow [1] [2]. Peripheral thrombocytopenia occurs secondary to the fixation of antiplatelet autoantibodies or immune complexes on the platelet membrane, a process that will lead to the phagocytosis of the thrombocytes by the macrophages. The mechanism of the occurrence of autoantibodies remains unknown to this day [3] [4]. Recent studies show that the disorder of the humoral immune response is based on the complex interaction between antigen-presenting cells and $\mathrm{T}$ and $\mathrm{B}$ lymphocytes. The role of antigen-presenting cell lies with the thrombocyte. The glycoproteins at the level of the platelet membrane acquire antigenic traits at the moment when immune tolerance is lost towards its own antigens. Thus, the activation of the immune system that will produce antibodies, the main target of which are membrane glycoproteins, takes place. The antibodies are directed to certain surface structures, the most common antigens being glycoproteins IIb/IIIa and Ib/IX [5]-[7]. The platelets on which antibodies are fixed are sequestrated and destroyed in great majority, in the spleen, but the liver and the reticuloendothelial system of the marrow can also play an important role in platelet sequestration. The studies with label platelets showed a major shortening of the lifespan of platelets in the circulation of patients with ITP. The median survival time is between 2 - 3 days with the possibility of dropping to a few minutes.

Secondary immune thrombocytopenia could develop in the context of disorders such as autoimmune diseases (systemic lupus erythematosus, antiphospholipid syndrome, autoimmune thyroiditis or the Evans syndrome), myeloproliferative syndromes (chronic lymphocytic leukemia), infections with the virus of hepatitis B or C, infection with HIV or with Helicobacter pylori [8]. Moreover, secondary thrombocytopenia could occur in pregnancy or be drug-induced [9]. In case of associations with autoimmune pathologies, a phenomenon of cross-reactivity between the anti-platelet antibodies and other antibodies such as the anti-nuclear, the anti-double-stranded DNA or the anti-cardiolipin will most likely take place.

This study aims to emphasize the involvement of some autoimmune disorders in the pathogenesis of secondary immune thrombocytopenia.

\section{Material and Method}

The current study is of an observational type and aims to study the occurrence of secondary thrombocytopenia in patients with autoimmune diseases, such as systemic lupus erythematosus or the antiphospholipid syndrome. The study group comprises 40 patients registered with the Hematology Clinic within "St. Spiridon" Emergency University Hospital of Iași, Romania. The patients included in the study are aged between 38 - 65 years old, 25 of them are female and 15 male. 30 of the patients come from the rural area and 10 from the urban area. The study was conducted over a period of 10 months. The patients were distributed into two groups:

- Asymptomatic patients diagnosed with thrombocytopenia following routine tests;

- Patients with hemorrhagiparous symptomatology (petechiae, ecchymoses, epistaxis, gingivorrhagia), going to the doctor in order to determine the etiology of the hemorrhagiparous syndrome.

The common criterion for the patients' inclusion in the study was thrombocytopenia.

None of the patients included in the study, prior to the occurrence of thrombocytopenia, used medication involved in its production, nor were they diagnosed with other active pathologies that would justify the decreased platelet count. The patients included in the study group signed an informed consent form expressing their agreement to be part of the research group. The study complied with law 677/2001 regarding the collection, use and processing of personal data. The research was conducted in strict accordance with the bioethical norms provided by EU legislation.

The following steps of the diagnosis protocol have been respected for both groups:

- Platelet count with the help of an automatic analyzer by the method of hydrodynamic focusing (venous 
blood collected in vacutainer containing the anticoagulant tripotassium/dipotassium/disodium—K3 EDTA); the samples were analyzed within 6 hours of collection.

- Dosage of platelet antibodies through the ELISA method (venous blood collected in vacutainers without anticoagulant, as permitted by the vacuum; the serum is separated through centrifugation, working as quickly as possible or refrigerating it $\left(2^{\circ} \mathrm{C}-8^{\circ} \mathrm{C}\right)$ no more than 5 days or freezing it at $\left.-20^{\circ} \mathrm{C}\right)$ [10] [11].

- Determination of anti-nuclear antibodies by fluorescence enzyme immunoassay technique (FEIA) [12].

- Dosing anti-double-stranded DNA by the ELISA method [13].

- Dosing anti-cardiolipin IgG antibodies by the immunochemical methods with chemiluminescence immunoassay (CLIA) detection [14].

The main aim of the study was to establish the etiology of thrombocytopenia, thus emphasizing the involvement of autoimmune diseases in the pathogenesis of chronic immune thrombocytopenia.

\section{Results and Discussion}

- Platelet count

This determination revealed a low platelet count in the entire study group. The series of values of platelets (PLT) in the blood, with a variance of $32.8 \%$ was within the range of $33-87 \times 10^{3} / \mu \mathrm{L}$, the group average being of $60.20 \pm 19.75 \times 10^{3} / \mu \mathrm{L}$. The results are shown in Table 1 .

- Dosage of anti-platelet antibodies

$80 \%$ of the patients showed positive anti-platelet antibodies, with PLT values in the range $33-87 \times 10^{3} / \mu \mathrm{L}$, recording an average value of $59.13 \pm 20.19 \times 10^{3} / \mu \mathrm{L}$, slightly lower compared to the average value in patients with negative anti-platelet antibodies $(\mathrm{p}=0.852)$. Results are reported in Table 2 and Figure 1.

The antiplatelet antibodies are considered to be an important determination in the diagnosis of immune thrombocytopenia. Their involvement in the etiopathogenesis of primary immune purpura is explained by the property of these autoantibodies to act directly on glycoprotein (GP) complexes from the level of the platelet membrane, of GP IIb/IIIa or GP Ib/IX type. The physiological role of the glycoprotein complexes is that of mediating the interaction between platelets in the blood and the vascular subendothelium of damaged blood vessels. This interaction results in stopping the hemorrhage from the damaged vessel due to the adhesion and aggregability properties of the thrombocytes. When antiplatelet antibodies are present, the function of the glycoproteins is disturbed, which will lead to platelet dysfunctions and platelet hyper-destruction. Hyper-destruction is generated by attaching antibodies to the platelet membrane, causing either the phagocytosis of the platelet or the activation of the lytic complement and mechanisms. The antiplatelet antibodies can also be connected to the megakaryocytes, in which case the hyper-destruction is due to the decreased thrombopoeisis [15]. In a clinical environment, the platelet pathology is reflected by bleeding disorders of varying intensities from epistaxis, gingivorrhagia, ecchymoses, petechiae to digestive, cerebral meningeal and retinal hemorrhaging.

- Dosage of anti-nuclear antibody

Only one patient (10\%) presented positive anti-nuclear antibodies, registering a value of $75 \times 10^{3} / \mu \mathrm{L}$ and in

Table 1. PLT descriptive indicators $* 10^{3} / \mu \mathrm{L}$.

\begin{tabular}{|c|c|c|c|c|c|c|c|c|}
\hline \multirow{2}{*}{ Parameter } & \multirow{2}{*}{ No. } & \multirow{2}{*}{ Average } & \multirow{2}{*}{ Std. Deviation } & \multirow{2}{*}{ Std. Error } & \multicolumn{2}{|c|}{ Confidence Range 95\% } & \multirow{2}{*}{ Min } & \multirow{2}{*}{ Max } \\
\hline & & & & & $-95 \%$ CI & $+95 \% \mathrm{CI}$ & & \\
\hline Total & 40 & 60.20 & 19.75 & 6.25 & 46.07 & 74.33 & 33 & 87 \\
\hline
\end{tabular}

Table 2. Descriptive indicators of PLT $* 10^{3} / \mu \mathrm{L}$ according to anti-platelet Ab.

\begin{tabular}{|c|c|c|c|c|c|c|c|c|c|}
\hline \multirow{2}{*}{ Anti-Platelet Ab } & \multirow{2}{*}{ No. } & \multirow{2}{*}{ Average } & \multirow{2}{*}{ Std. Deviation } & \multirow{2}{*}{ Std. Error } & \multicolumn{2}{|c|}{ Confidence Range 95\% } & \multirow{2}{*}{ Min } & \multirow{2}{*}{ Max } & \multirow{2}{*}{ Test F (ANOVA) p } \\
\hline & & & & & $-95 \% \mathrm{CI}$ & $+95 \%$ CI & & & \\
\hline Negative & 8 & 64.50 & 24.75 & 17.50 & -157.86 & 286.86 & 47 & 82 & \\
\hline Positive & 32 & 59.13 & 20.19 & 7.14 & 42.25 & 76.00 & 33 & 87 & 0.752 \\
\hline Total & 40 & 60.20 & 19.75 & 6.25 & 46.07 & 74.33 & 33 & 87 & \\
\hline
\end{tabular}


two patients (20\%) the result was equivocal, recording PLT values of 45 and $51 \times 10^{3} / \mu \mathrm{L}$ respectively with no significant differences from the average of the group with negative anti-nuclear $\mathrm{Ab}(\mathrm{p}=0.564)$. The results are shown in Table 3 and Figure 2.

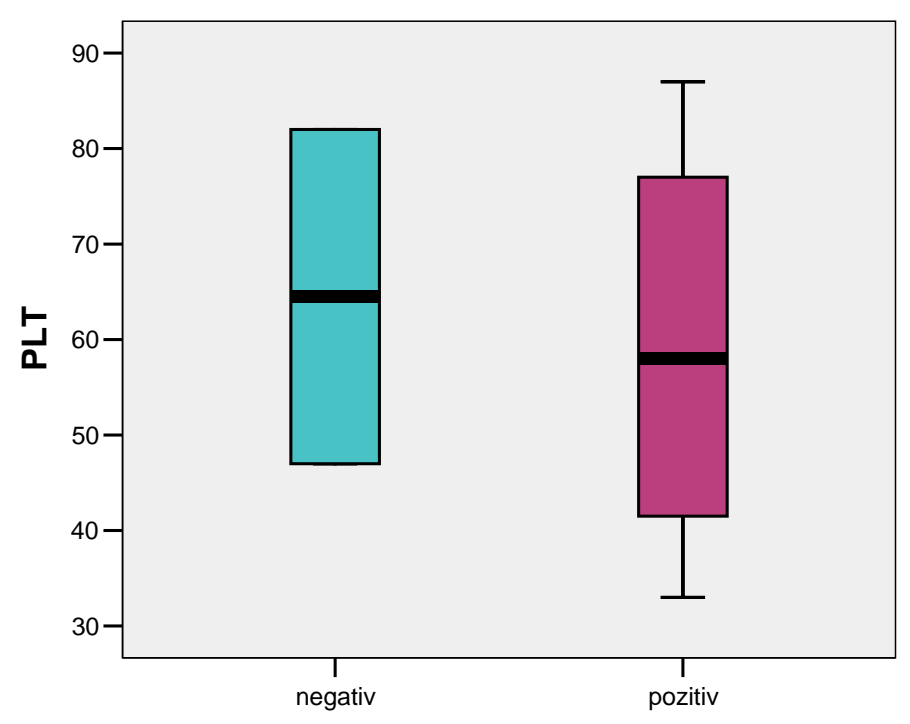

Ac antiTrombocitari

Figure 1. PLT average values $* 10^{3} / \mu \mathrm{L}$ according to the anti-platelet antibodies.

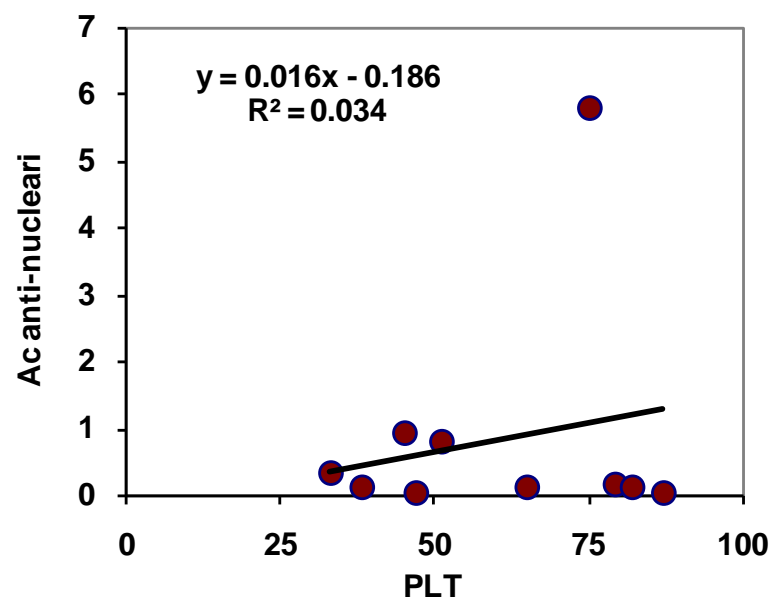

Figure 2. PLT correlation with anti-nuclear antibodies.

Table 3. PLT descriptive indicators $* 10^{3} / \mu \mathrm{L}$ according to anti-nuclear Ab.

\begin{tabular}{|c|c|c|c|c|c|c|c|c|c|}
\hline \multirow{2}{*}{ Anti-Nuclear Ab } & \multirow{2}{*}{ No. } & \multirow{2}{*}{ Average } & \multirow{2}{*}{ Std. Deviation } & \multirow{2}{*}{ Std. Error } & \multicolumn{2}{|c|}{ Confidence Range 95\% } & \multirow{2}{*}{ Min } & \multirow{2}{*}{ Max } & \multirow{2}{*}{ Test $\mathrm{F}$ (ANOVA) $\mathrm{p}$} \\
\hline & & & & & $-95 \% \mathrm{CI}$ & $+95 \% \mathrm{CI}$ & & & \\
\hline Negative & 7 & 61.57 & 22.23 & 8.40 & 41.02 & 82.13 & 33 & 87 & \multirow{4}{*}{0.564} \\
\hline Positive & 1 & 75.00 & & & & & 75 & 75 & \\
\hline Equivocal & 2 & 48.00 & 4.24 & 3.00 & 9.88 & 86.12 & 45 & 51 & \\
\hline Total & 10 & 60.20 & 19.75 & 6.25 & 46.07 & 74.33 & 33 & 87 & \\
\hline
\end{tabular}


Bases on the cases studied, the individual values of anti-nuclear antibodies do not significantly correlate with PLT values, however, a weak direct correlation $\left(r=+0.186 ; R^{2}=0.0347, p=0.606\right)$ does stand out.

The anti-nuclear antibodies belong to a large family of autoantibodies that react with antigens present in the cell nucleus and have a major role in the diagnosis of autoimmune diseases. The test performed uses recombinant human proteins as antigens, quakitatively detects ANA antibodies, which is useful in screening the following collagen diseases: SLE, scleroderma, mixed connective tissue disease, polymyositis/dermatomyositis and the Sjögren's syndrome. A positive result requires a continuation of the investigation, demanding specific autoantibodies, depending on the clinical suspicion.

- Dosage of anti-double-stranded DNA

Only 20\% of the patients showed positive anti-double stranded DNA antibodies, recording PLT values in the range between $75-79 \times 10^{3} / \mu \mathrm{L}$, average value of $77 \pm 2.83 \times 10^{3} / \mu \mathrm{L}$ being significantly increased compared to the average value $\left(56 \pm 19.99 \times 10^{3} / \mu \mathrm{L}\right)$ recorded in patients with negative anti-double stranded DNA antibodies $(\mathrm{p}=$ 0.049). The results are reported in Table 4.

The individual values of anti-DNA antibodies are in a direct moderate correlation with the platelets, however, this correlation is not significant from a statistical viewpoint $(r=+0.408$; $R 2=0.1664, p=0.242)$. This is shown in Figure 3. The simultaneous presence of anti-nuclear and anti-double stranded DNA antibodies is observable in 10\% of the patients, association which defines the existence of SLE. The anti-double stranded DNA antibodies (anti-dsDNA) represent the mark of SLE. The prevalence of anti-dsDNA antibodies in SLE patients is of $60 \%-90 \%$, depending on the detection method used and the degree of activity of the disease. Anti-dsDNA antibodies can be occasionally detected in patients with other autoimmune diseases as well, in viral infections (Epstein-Barr, hepatitis B), after the administration of certain drugs (hydralazine, interferon, TNF blockers) and, in rare cases, in healthy people, $85 \%$ of them being able to develop SLE within 5 years of the initial detection of anti-DNA antibodies. The patients studied also showed positive antiplatelet antibodies, which makes out a case for the association of a collagen disease (SLE) with the chronic immune pathology (secondary ITP).

SLE is an autoimmune disease affecting multiple organs and systems in the body, without so far having a well-established etiology. It is characterized by an abnormal production of antibodies that harm the healthy tissues. The skin, the bone marrow, the kidneys, the joints, the heart and the brain could be affected. The hematological disorders in SLE include thrombocytopenia, anemia and leukopenia. Thrombocytopenia is a consequence of

Table 4. PLT descriptive indicators * $10^{3} / \mu \mathrm{L}$ according to anti-double stranded DNA antibodies.

\begin{tabular}{ccccccccccc}
\hline $\begin{array}{c}\text { Anti-Double Stranded } \\
\text { DNA Antibodies }\end{array}$ & No. & Average & Std. Deviation & Std. Error & \multicolumn{2}{c}{ Confidence Range 95\% } & Min & Max & Test F (ANOVA) p \\
\hline Negative & 8 & 56.00 & 19.99 & 7.07 & 39.29 & 72.71 & 33 & 87 & \\
Positive & 2 & 77.00 & 2.83 & 2.00 & 51.59 & 102.41 & 75 & 79 & 0.049 \\
Total & 10 & 60.20 & 19.75 & 6.25 & 46.07 & 74.33 & 33 & 87 &
\end{tabular}

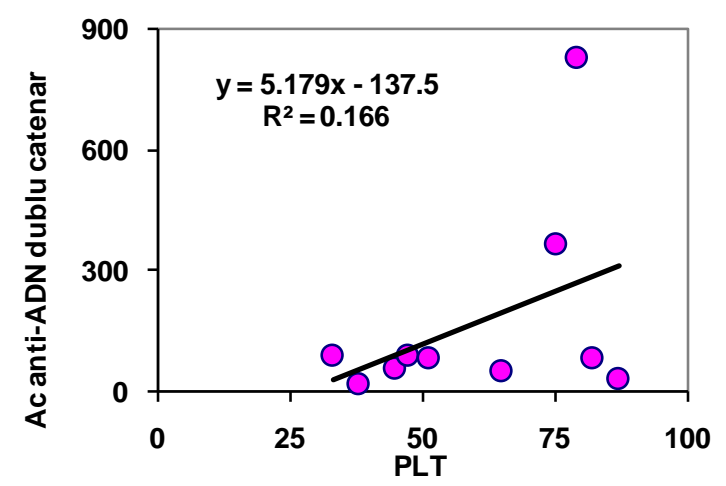

Figure 3. PLT correlation with anti-double-stranded DNA antibodies. 
SLE activity. It could occur as a side effect of immunosuppressive medications used in SLE or as a result of the activity of some autoantibodies directed against the thrombopoietin [16]. In the case of the study group analyzed, none of the patients followed immunosuppressive therapy, nor did they present a picture of pancytopenia reflecting the inhibition of the bone marrow. The decreased platelet count is not explained by a central mechanism in the patients studied, but is due to a peripheral immunological mechanism of cross-reactivity between the antiplatelet, the antinuclear and the anti-double-stranded DNA antibodies.

- Dosage of anti-cardiolipin antibodies

The anti-cardiolipin antibodies belong to the group of antiphospholipid antibodies specific for anionic phospholipids (negatively charged), components of cell membranes. The anti-cardiolipin antibodies are often present in people with the antiphospholipid syndrome. There are 2 clinical forms of the antiphospholipid syndrome: primary (53\% of cases) or in association with other autoimmune diseases (SLE, Sjögren's syndrome, scleroderma, mixed connective tissue disease, rheumatoid arthritis). The specialized literature cites the increased frequency of the antiphospholipid syndrome in patients with SLE [17].

$20 \%$ of the patients exceed the reference value of IgG anti-cardiolipin antibodies, recording a platelet value of 45 and $75 \times 10^{3} / \mu \mathrm{L}$, the average value of $\left(60 \pm 21.21 \times 10^{3} / \mu \mathrm{L}\right)$ not being significantly different from the average of the group with negative anti-cardiolipin antibodies IgG $\left(60.25 \pm 20.91 \times 10^{3} / \mu \mathrm{L}\right)(\mathrm{p}=0.988)$.

The individual values of IgG anti-cardiolipin antibodies are in a slightly direct correlation with the platelets, however, this correlation is not significant from a statistical perspective $\left(r=+0.273 ; R^{2}=0.0747, p=0.445\right)$. The results are presented in Table 5 and Figure 4.

\section{Conclusions}

Accurately establishing the factors involved in the etiology of autoimmune thrombocytopenia leads to the correct determination of the type of thrombocytopenia. The primary thrombocytopenia involves the development of anti-platelet antibodies at the level of the platelet membrane, without knowing the exact cause of these immune disorders. The secondary immune thrombocytopenia also implies the existence of anti-platelet antibodies, however, their presence is considered to be secondary to some associated pathologies. The results of our study highlighted the involvement of autoimmune diseases in the pathogenesis of chronic immune purpura. Secondary to

Table 5. Descriptive indicators of PLT $* 10^{3} / \mu \mathrm{L}$ according to IgG anti-cardiolipin antibodies.

\begin{tabular}{|c|c|c|c|c|c|c|c|c|c|}
\hline \multirow{2}{*}{$\begin{array}{l}\text { Anti-Cardiolipin } \\
\text { Antibodies IgG }\end{array}$} & \multirow{2}{*}{ No. } & \multirow{2}{*}{ Average } & \multirow{2}{*}{ Std. Deviation } & \multirow{2}{*}{ Std. Error } & \multicolumn{2}{|c|}{ Confidence Range 95\% } & \multirow{2}{*}{ Min } & \multirow{2}{*}{$\operatorname{Max}$} & \multirow{2}{*}{ Test F (ANOVA) p } \\
\hline & & & & & $-95 \%$ CI & $+95 \% \mathrm{CI}$ & & & \\
\hline Negative & 8 & 60.25 & 20.91 & 7.39 & 42.77 & 77.73 & 33 & 87 & \\
\hline Positive & 2 & 60.00 & 21.21 & 15.00 & -130.59 & 250.59 & 45 & 75 & 0.988 \\
\hline Total & 10 & 60.20 & 19.75 & 6.25 & 46.07 & 74.33 & 33 & 87 & \\
\hline
\end{tabular}

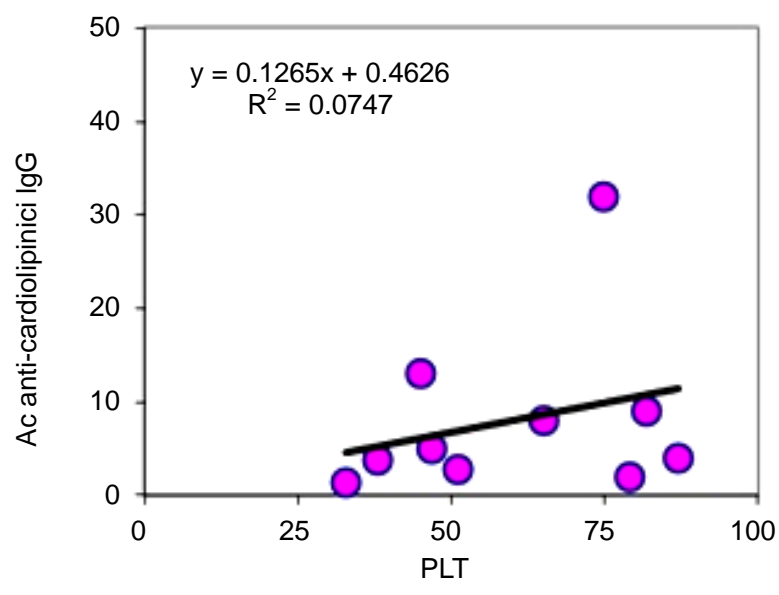

Figure 4. PLT correlation with IgG anti-cardiolipin antibodies. 
the results of our study, the immunological tests performed in patients with thrombocytopenia is essential, due to the fact that the correct determination of the etiologic agent of the disease will lead to the adoption of a correct therapeutic approach.

In patients who have evidence that thrombocytopenia is associated with autoimmune pathology we recommend initiation of appropriate therapy of autoimmune disease. Treatment of immune pathology will have favorable effects on peripheral thrombocytopenia. Patients lacking autoimmune diseases will be further investigated in order to establish the etiologic agents involved in the pathogenesis of chronic immune thromboctytopenia.

\section{References}

[1] Dănăilă, C. (2004) Hematologie Generala.

[2] Braunwald, Fauci, Kasper, Hauser, Longo and Jameson (2002) Principios de Medicina Interna. 15th Edition, McGraw Hill, New York, 882-884.

[3] McMillan, R. (2007) The Pathogenesis of Chronic Immune Thrombocytopenic Purpura. Seminars in Hematology, 44, S3-S11. http://dx.doi.org/10.1053/j.seminhematol.2007.11.002

[4] Thota, S., Kistangari, G., Daw, H. and Spiro, T. (2012) Immune Thrombocytopenia in Adults: An Update. Cleveland Clinic Journal of Medicine, 79, 641-650. http://dx.doi.org/10.3949/ccjm.79a.11027

[5] Provan, D. (2009) Characteristics of Immune Thrombocytopenic Purpura: A Guide for Clinical Practice. European Journal of Haematology, 71, 8-12. http://dx.doi.org/10.1111/j.1600-0609.2008.01207.x

[6] Anoop, P. (2012) Immune Thrombocytopenic Purpura: Historical Perspective, Current Status, Recent Advances and Future Directions. Indian Pediatrics, 49, 811-818. http://dx.doi.org/10.1007/s13312-012-0195-1

[7] Kuwana, M. and Ikeda, Y. (2005) The Role of Autoreactive T-Cells in the Pathogenesis of Idiopathic Thrombocytopenic Purpura. International Journal of Hematology, 81, 106-112. http://dx.doi.org/10.1532/IJH97.04176

[8] Cines, D.B., Liebman, H. and Stasi, R. (2009) Pathobiology of Secondary Immune Thrombocytopenia. Seminars in Hematology, 46, S2-S14. http://dx.doi.org/10.1053/j.seminhematol.2008.12.005

[9] McCrae, K. (2011) Immune Thrombocytopenia: No Longer "Idiopathic”. Cleveland Clinic Journal of Medicine, 78, 358-373. http://dx.doi.org/10.3949/ccjm.78gr.10005

[10] Laboratory Corporation of America, Directory of Services and Interpretive Guide (2010) Platelet Autoantibody Panel, Whole Blood. Platelet Antibody Profile, Serum. https://www.labcorp.com/wps/portal/

[11] Laborator Synevo (2010) Referintele specifice tehnologiei de lucru utilizate. https://www.synevo.ro/anticorpiantitrombocitari-liberi-in-ser/

[12] Laborator Synevo (2010) Referintele specifice tehnologiei de lucru utilizate. https://www.synevo.ro/anticorpi-antinucleariana/

[13] Laborator Synevo (2013) Referintele specifice tehnologiei de lucru utilizate. https://www.synevo.ro/anticorpi-anti-adn-dublu-catenar/

[14] Laborator Synevo (2013) Referintele specifice tehnologiei de lucru utilizate. http://www.synevo.ro/anticorpi-anticardiolipinici-igg/

[15] Adam, C. and Douglas, B. (2010) Immune Thrombocytopenia. Hematology, 374-384.

[16] Ktona, E., Barbullushi, M., Backa, T., Idrizi, A., Shpata, V. and Roshi, E. (2014) Evaluation of Thrombocytopenia in Systemic Lupus Erythematosus and Correlation with Different Organs Damages. Materia Socio Medica, 26, 122-124. http://dx.doi.org/10.5455/msm.2014.26.122-124

[17] Wendi, L. (2010) Antiphospholipid Antibody Syndrome. Hematology, 233-239. 